\title{
Conceito de ConsciênCia em Vigotski
}

\author{
Gisele Toassa ${ }^{1}$ \\ Instituto de Psicologia - USP
}

Este artigo persegue o conceito de consciência na obra de Vigotski, o principal problema de sua psicologia. Resume a importância do contexto sociopolítico da União Soviética para o desenvolvimento de sua teoria, que se iniciou com influências da reflexologia e do pavlovismo, integrando progressivamente os amplos conhecimentos do autor (nas artes, na filosofia clássica e marxista) até a neuropsicologia e a psicologia experimental. Através da leitura de trabalhos produzidos de 1924 a 1934, este artigo revisa as ocorrências semânticas da palavra consciência, identificando seus fundamentos monistas e materialistas, extraindo seus sentidos principais e incluindo o conceito no enfoque históricocultural. O conceito é desmembrado em suas três acepções basilares (processo de tomada de consciência da realidade externa e interna; atributo de conteúdos e processos psicológicos; sistema psicológico) que se articulam, produzindo um dos fundamentos da psicologia geral vigotskiana e articulando neuropsicologia, ética e ontologia.

Descritores: Vygotsky, Lev Semenovich, 1896-1934. Consciência.

História da Psicologia. Neuropsicologia. Luria, Alexander Romanovich, 1902-1977.

$\mathrm{L}$ eningrado, II Congresso Nacional de Psiconeurologia, 6 de janeiro de 1924. Um recém-chegado da Bielo-Rússia apresenta a comunicação intitulada "Os métodos de investigação reflexológicos e psicológicos". Suas

1 Doutoranda em Psicologia Escolar e do Desenvolvimento Humano pelo Instituto de Psicologia - USP. Meus ternos agradecimentos aos revisores deste artigo, Suely Amaral Mello (UNESP-Marília), orientadora deste trabalho iniciado no mestrado, e Sandro Henrique Vieira de Almeida, historiador da psicologia soviética (PUC-SP). Apoio financeiro: CAPES e CNPQ. Endereço para correspondência: Rua Caiubi, 372, apto. 22, Perdizes, São Paulo, SP. CEP 05010-000. Endereço eletrônico: gtoassa@yahoo. com.br 
idéias são transformadas em texto e publicadas na coletânea "Psicologia e Marxismo", organizada por Kornilov, um ano mais tarde. Estão inaugurados os dez anos de fúria criadora do jovem Lev Semenovich Vigotski, decepados pela tuberculose em junho de 1934 (Luria, 1992; Vygotski, 1991).

O texto apresentado demarca a primeira posição de Vigotski no campo metodológico, já imersa num debate que se revelaria crucial para o desenvolvimento de seu enfoque: o introspeccionismo subjetivista versus a ciência dos reflexos, objetivista; a psicologia é ferramenta de uma sociedade que se reconstrói na luta de forças revolucionárias e contra-revolucionárias. A nova ciência ganha conotações político-ideológicas e se expande dos laboratórios experimentais para as aplicações sociais.

Desde a Rússia tzarista, despontava uma eminente tradição de estudo da então denominada atividade nervosa superior: discípulo de Séchenov e Cion, Pavlov fora laureado com o Nobel em 1904. Tempo de grandes desafios: nos anos que seguem a Revolução de Outubro (1917), a fome convive com o ordenamento científico da cosmovisão socialista. Em 1921, Lênin assina um decreto assinalando "os incríveis serviços do acadêmico Ivan Petrovich Pavlov, que são de enorme significância para a classe trabalhadora de todo o mundo" (Nobel Foundation, 1967). Pavlov recebe novas condições de trabalho do governo socialista - sua equipe chega a ser composta por 300 pessoas - e é nas duas décadas seguintes que publicará suas obras de maior alcance teórico (Pessotti, 1979), não obstante o próprio Ivan Petrovich sofresse na pele a grande fome que se seguiu à revolução socialista.

As palavras de Lênin ilustram a grande importância que as ciências e a tecnologia vão adquirindo no regime soviético, bem como a crença geral no meio científico da época de que a ciência dos reflexos de Pavlov forneceria base para uma nova visão do psiquismo humano. Conforme Shuare (1990), o comando soviético considerava necessário desenvolver uma visão materialista e dialética de ciências naturais e sociais. Neste período de grande agitação revolucionária, relativa liberdade de expressão e disputas de poder na cúpula do regime socialista - especialmente após a morte de Lênin em 1924 -, floresce um breve período de riquíssimas contribuições intelectuais e artísticas (Reis Filho, 2003).

Vigotski desponta neste cenário de penúria material e entusiasmo socialista - que Valsiner e Van der Veer (1996) chegam a denominar de "missionário", 
tamanho o empenho do autor na edificação da nova psicologia -, de criativo entrecruzamento de ciência, arte e filosofia ao qual, com seu gênio intelectual judaico e iluminista, terá muito a acrescentar. Em 1923, Kornilov divulga no I Congresso de Nacional de Psiconeurologia alguns princípios para uma psicologia marxista, tais como: a matéria tem caráter primário com respeito à consciência; a psique é propriedade da matéria altamente (e socialmente) organizada; a dialética deve ser aplicada criativamente como método de investigação. Com esta comunicação, o autor intensificava os ataques públicos contra Chelpanov, diretor do Instituto de Psicologia de Moscou (Valsiner \& Van Der Veer, 1996).

Outros autores antes de Kornilov já haviam se aventurado a propor princípios marxistas na edificação da psicologia, mas, desta feita, há uma conquista política importante: ainda em 1923, o Conselho Científico Estatal destitui Chelpanov da direção do Instituto, substituindo-o por Kornilov (Leontiev, 1996). Nessa época, proliferavam diversas escolas da Psicologia: psicanálise, personalismo, pedologia, introspeccionismo entre outras, embora com o passar dos anos fossem silenciadas as tradições consideradas burguesas (Valsiner \& Van Der Veer, 1996).

O novo diretor era o criador da chamada reactologia, ciência das reações, que então defendia a combinação de relatos pessoais com o estudo das reações ocultas ao observador, do dispêndio de energia no trabalho entre outros temas. Não houve, entretanto, grande proximidade entre Kornilov, sempre envolvido com tarefas administrativas do Instituto, e Vigotski, cuja base de pesquisa estendeu-se ao laboratório da Academia de Educação Comunista (Valsiner \& Van Der Veer, 1996). Após sua apresentação no II Congresso de Psiconeurologia, Vigotski foi convidado pelo diretor a unir-se ao corpo de pesquisadores de um Instituto em remodelação, no qual, a uma certa distância de Pavlov, avolumavam-se as críticas à idéia de que todo comportamento poderia ser explicado pelo reflexo condicionado. Com a presença de jovens como Luria, Leontiev, Morozova entre outros, buscava-se demarcar a posição de um novo grupo científico. ${ }^{2}$

Vigotski é um pensador complexo, e sua obra de nenhum modo pode ser enquadrada na ciência dos reflexos, na reactologia ou qualquer outra ex-

2 Luria e Leontiev trabalhavam para descobrir as bases materiais do fenômeno psicológico, usando concepções pavlovianas (Leontiev, 1996). 
pressão introspeccionista ou objetivista clássica. Educou-se por meio do materialismo histórico e dialético, dos conhecimentos científicos e filosóficos, clássicos ou de sua época, bem como de seus próprios trabalhos experimentais (Almeida, 2004), sendo o principal criador do enfoque histórico-cultural. Mas seus primeiros trabalhos no Instituto indicam alguma afinidade teórica para com Kornilov, Bekhterev e Pavlov e, até a composição do revolucionário "Significado histórico da crise na psicologia", vários textos do autor defendem a exploração da Psicologia como ciência dos reflexos condicionados, debate dos estudiosos da então chamada atividade nervosa superior. Sua postura era a de uma crítica propositiva e, já em 1924, ele reconhecia, como outros autores do cenário internacional, a crise de sua ciência (Alvarez \& Río, 1991).

O Vigotski de 1924 procura levar a unidade explicativa do reflexo condicionado às últimas conseqüências, e é com a terminologia da ciência dos reflexos que ele sintetiza algumas de suas primeiras idéias sobre a consciência, linguagem e inconsciente. O autor (1924-1934/1991) afirma que a investigação reflexológica deveria sofrer uma virada: os modestos experimentos clássicos de formação do reflexo condicionado já haviam atingido seu limite. O pensamento, inclusive por Vigotski, é considerado na época como reflexo inibido e a linguagem (interna ou externa) como um tipo de comportamento. A fala aparece como cadeias de perguntas e respostas, séries capazes de sofrer a influência de outros sistemas reflexos; trata-se de um meio de comunicação diante do qual a ciência dos reflexos sofre um impasse teórico e metodológico. Tal impasse explica-se, segundo minha compreensão, porque homens como Pavlov e Bekhterev eram fisiólogos instruídos no estudo do comportamento animal. Pavlov, no entanto, acabou por desenvolver uma concepção de linguagem como "segundo sistema de sinalização", como novo padrão de sinalização constituído de estímulos verbais, diferentemente da simples sinalização sensorial (Pavlov, 2005). A maior intimidade com os territórios da língua, literatura e semiologia possibilitou a Vigotski superar o dualismo reflexológico e enxergar na socialidade da linguagem a origem das interações que compõem a consciência humana. Vigotski abraçou a formulação de uma obra materialista que não se recusasse a estudar a consciência, e tampouco fosse capturada nos becos sem saída do introspeccionismo. Neste momento de sua obra, a saída é considerar a consciência como a própria interação entre sistemas de reflexo: 


\section{Conceito de Consciência em Vigotski}

também a própria consciência ou a tomada de consciência dos nossos atos e estados deve ser interpretada como sistema de transmissores de uns reflexos a outros que funcionam corretamente em cada momento consciente. Quanto maior seja o ajuste com que qualquer reflexo interno provoque uma nova série em outros sistemas, mais capazes seremos de prestar-nos contas de nossas sensações, comunicá-las aos demais e vivê-las (senti-las, fixá-las nas palavras etc). (Vygotski, 1924/1991, p. 3, tradução nossa)

A consciência aparece, pois, como um sistema de transmissores, um sistema que adquire a qualidade de sensações secundárias. Existiriam, basicamente, reflexos internos e externos, como duas categorias gerais de sistemas de reflexos: um reflexo interno pode tornar-se palavra falada, e é neste tornar-se que atua o referido sistema. O sistema é regido por leis causais desta estruturação em complexos, com diferentes tipos, de formas de interação dentro dos subsistemas e na totalidade dos sistemas (Vygotski, 1924-1934/1991). Os experimentos de associação de palavras, por exemplo, realizam-se com a colaboração de sistemas próximos. Quando uma emoção é traduzida em palavras, temos um exemplo de interação sistêmica. Surgem já dois termos que não abandonarão Vigotski: estrutura e sistema, os quais se enriquecem com a evolução teórica, metodológica e empírica do enfoque histórico-cultural e se imiscuem na sua discussão do conceito de consciência. Estes termos indicam que o cérebro não tem um funcionamento organizado a priori, que as estruturas funcionais fundamentam-se na capacidade de formação de novas conexões neurais sistemicamente organizadas. A palavra é unidade básica do sistema dos reflexos da consciência, isto é, dos reflexos que servem para refletir a influência de outros sistemas ${ }^{3}$.

A palavra falada pelo outro e ouvida por mim é um excitante, a falada por mim é um reflexo que cria excitantes a serem ouvidos pelo outro e por mim. São reflexos reversíveis nos quais reside a fonte do comportamento e da consciência, servindo à coordenação coletiva do comportamento, perante o

3 Assim, Vigotski propõe uma ciência dos reflexos também aplicada à linguagem, em que o relato verbal é visto como uma forma de experimento, não como simples informe de processos internos, carente de precisão, mas sim, como uma sequiência de excitações e respostas motoras, isto é, de reflexos. 


\section{Gisele Toassa}

qual a consciência nunca é pensada como independente do mundo e com uma tendência à progressiva integração entre diversos sistemas de conduta.

O mecanismo da consciência de si próprio (auto-conhecimento) e de reconhecimento dos demais é idêntico: temos consciência de nós mesmos porque a temos dos demais e pelo mesmo mecanismo, porque somos com respeito a nós o mesmo que os demais com respeito a nós. Reconhecemos-nos a nós só na medida em que somos outros para nós, isto é, pelo quanto somos capazes de perceber de novo os reflexos próprios como excitantes. (Vygotski, 1924-1934/1991, p. 12, tradução nossa)

A consciência de si implica, pois, numa relação de alteridade da pessoa para consigo mesma, adquirida através da auto-estimulação produzida pela palavra. O conhecimento e o reconhecimento são funções da palavra, sendo que uma outra pessoa está sempre presente na sua formulação. Aparece já aqui a idéia de desdobramento de funções entre pessoas e sua síntese numa só, uma das leis fundamentais de desenvolvimento das funções psíquicas superiores. Noutro texto jovem (1925), a consciência aparece como vivência das vivências, em analogia à forma pela qual as simples sensações são sensações dos objetos (Vygotski, 1924-1934/1991). Este é o embrião da idéia de segunda conexão neurológica na mediação da atividade, possivelmente inspirada em Pavlov, que ganha maior consistência epistemológica no decorrer da obra vigotskiana.

Mas essa primeira conceituação de consciência é problemática. A palavra restringe-se ao nível da sensação e da estimulação que explicam, aqui, o psiquismo, sem avançar muito com relação ao associacionismo tradicional. Seu aspecto essencial são as relações interfuncionais, as traduções das relações entre sistemas de reflexos cerebrais. Mas como estas traduções se efetuam entre os vários tipos de reflexo? Quais são exatamente os sistemas de reflexo, que agora parecem contemplar várias faculdades idealistas da alma (como associação, linguagem, emoção etc.)? O próprio Vygotski (1924-1934/1991) mostra-se insatisfeito com a idéia de reflexo, indicando que "comportamento" seria um termo mais totalizante, que abarca também os reflexos condicionados tradicionais.

Num enquadramento teórico semelhante, "A consciência como um problema de psicologia do comportamento" (Vygotski, 1925/1991) polemiza com a ciência dos reflexos que, para Vygotski, perde-se no dualismo e no 
epifenomenalismo - pois admite a existência dos fenômenos de consciência, mas se recusa a estudá-los com os métodos da reflexologia; aceita-os, embora os tome como simples sensações das cadeias mecanicistas de comportamento. As sondagens introspeccionistas deveriam ser abandonadas. O texto indicado acima avança as posições do autor nos seguintes aspectos:

1) Metodológico: para se estudar os fatos da consciência, é preciso trasladá-los a um idioma objetivo, materializá-los (Vygotski, 1924-1934/1991). Outro passo é restringir o reflexo condicionado aos fenômenos detectados nos experimentos pavlovianos, idéia também presente em Bekhterev.

2) Quanto às formas da experiência e na sua aquisição: o reflexo condicionado $^{4}$ (como o autor também defende incidentalmente na Psicologia Pedagógica) é considerado como meio básico de aquisição da experiência comportamental. Ele é a impressão neurológica que conjuga as aquisições evolutivas inatas, a experiência histórica do gênero humano, a de outros indivíduos (experiência social) e a duplicada (indicando a mediação do trabalho na relação indivíduo ambiente) (Vygotski, 1925/1991). Estas quatro fontes do comportamento são referências importantes para a escrita de sua "Psicologia Pedagógica". A consciência ainda aparece como interação entre sistemas de reflexos, no qual se dá uma luta entre os diversos tipos de reflexos pela posse do campo motor comum - sistemas reflexos que se vinculam, sendo que, de acordo com variáveis diversas, surgem focos de maior excitação no cérebro, possibilitando a um reflexo tornar-se dominante e inibir outros (idéia presente na fisiologia de Ukhtomski).

3) Indícios maiores da integração do marxismo em seu pensamento: o texto se abre com uma citação de Marx que ressalta a capacidade humana de planejamento das próprias ações, de duplicação da realidade na consciência por meio do trabalho humano e de adaptação ativa ao mundo externo. O papel do trabalho como formador da consciência insinua-se neste texto ${ }^{5}$.

4 Já existe uma ambigüidade do autor quanto à abrangência do conceito de reflexo: parece preferir, em substituição a ele, o termo comportamento (Vygotski, 1925/1991, p. 42), que, depois, também há de sacrificar pelas idéias de função psíquica superior e sistemas psicológicos.

5 Davidov e Radzikhovskii (1985, p. 44) indicam uma incompatibilidade entre as três acepções da palavra consciência neste texto: 1) como reflexo dos reflexos; 2) como estrutura do comportamento; e 3) como característica do trabalho humano. Discordo 
A Psicologia Pedagógica (Vigotski, 1926/2001c) apresenta a contribuição das mais importantes psicologias da época para o trabalho pedagógico. Aqui, a idéia de consciência surge aplicada ao papel de educar e de dirigir o desenvolvimento da criança, com atenção aos processos psicológicos de aquisição da consciência social. Maturam as incursões do autor no chamado eixo genético de investigação, ou seja, no estudo da ontogênese e filogênese da conduta humana. A aquisição da experiência do gênero humano e de outros indivíduos já é vista por ele como um processo dinâmico, ativo e dialético. A filogênese da conduta consciente é estudada na sua estrutura e natureza cerebral, aparecendo como um objeto de reflexão para o autor; existe já uma estratificação evolutiva dos tipos de reação, com uma dialética entre as reações humanas conscientes e as evolutivamente mais antigas. Os atos racionais, por exemplo, ao se repetirem, podem adquirir o perfil de simples reflexos - de condutas automáticas - e este aspecto seria fundamental para a execução de tarefas mais complexas - idéia que se reapresenta num dos últimos trabalhos do autor (2001a). Conforme Valsiner e Van der Veer (1996), na concepção do evolucionista russo Vagner (importante fonte de Vigotski), o instinto seria diferente do intelecto, conquanto instinto e intelecto tivessem o reflexo como origem comum.

Na relação entre razão-instinto-atividade aprofunda-se o monismo que o autor desenvolverá posteriormente: o homem é parte da natureza. Mas a reflexologia já mostrou seus limites: é difícil conciliá-la com as evidências de conduta humana voluntária, havendo também sérios problemas em todos os outros referenciais. A Psicologia estava entre a vida e a morte, e Vigotski, também. Ao sofrer uma séria crise de tuberculose, o autor escreve o texto que, para muitos, serviria como seu testamento para a continuidade do desenvolvimento da Psicologia: o explosivo "Significado Histórico da Crise na Psicologia” (1927/1991), proibido na União Soviética - como toda a obra de Vigotski - durante mais de 20 anos. Este texto só vem à luz em 1982.

$\mathrm{O}$ autor defende a formulação de uma psicologia geral que abstraia da

desta suposta incompatibilidade, defendendo que existe uma consistência interna nesta primeira conceituação de Vigotski: aqui o trabalho é visto como atividade, como a relação entre homem e mundo produzida pelo reflexo condicionado, e refletida também no segundo sistema de reflexos: a consciência. Existe já uma unidade de concepção em Vigotski que se desenvolve e ganha sua expressão histórico-cultural anos depois. 


\section{Conceito de Consciência em Vigotski}

diversidade dos fenômenos psíquicos um traço comum, próprio de todos ou da disciplina geral (Vygotski, 1927/1991), fazendo um balanço das contribuições de diversas escolas e as conquistando para uma psicologia marxista, com seu método inspirado no materialismo dialético. Tal psicologia deveria mediar temas e condições concretos de reflexão e atuação do psicólogo - tornando-se uma psicologia concreta do homem. Sem erro, pela abrangência e recorrência com que o autor trata o conceito de consciência, podemos dizer que este seria parte da disciplina geral, vindo a cobrir, no futuro, um amplo espectro de necessidades práticas. O teste da teoria para Vigotski deveria ser feito especialmente numa relação orgânica com a prática, como, assim podemos supor, era a prática clínica que o autor desenvolvia na pedologia e na reabilitação neuropsicológica ${ }^{6}$. A importância do conceito na educação reflete-se na preocupação do autor em educar os professores acerca dos meios para formar a consciência socialista dos alunos: a educação era uma demanda urgente na União Soviética socialista, que então contava milhões de analfabetos, além de muitas crianças desabrigadas e deficientes sem nenhum tipo de assistência (Kozulin, 1994).

A sociedade, sua história e sua cultura surgem como os fundamentos ontológicos da vida humana, superando os esquemas de comportamento reflexo, criando formas especificamente humana de determinismo, com uma regulação da conduta que não poderia ser reduzida ao comportamento animal. É o momento de conquistar a consciência como objeto de estudo para a nova psicologia: Vigotski entra em seu último e decisivo momento de produção (1928-1934), em que desenvolve, com seus discípulos, os fundamentos do enfoque histórico-cultural.

O binômio estímulo-resposta foi ajuizado por Vygotski (1931/1995) como o único método existente na psicologia experimental, partilhado por introspeccionistas e reflexólogos. Mas para o autor, a diferenciação do humano com relação ao animal dever-se-ia principalmente à apropriação de novos mediadores da conduta, especialmente signos e ferramentas. $\mathrm{O}$ autor aponta para a necessidade de uma análise dos processos baseados no signo, que introduzem uma verdadeira mudança de qualidade na relação homem-meio: para Vigotski, a ciência dos reflexos errou ao enquadrar o signo entre os demais estímulos sensoriais, ou a reação verbal entre outras tantas reações, pois a palavra não

6 Vigotski inspira-se na frase de Engels: "A prova do pudim é comê-lo" (Engels, 1880). 
é meramente um estímulo físico. O homem teria suplantado o padrão fixo, característico da natureza, no qual os animais respondem hereditariamente aos estímulos ambientais, ou adquirem novas informações sobre o ambiente a partir do reflexo condicionado (conceito amplo que também incluiria, em minha visão, o comportamento operante skinneriano): os signos são uma forma de auto-estimulação no domínio da conduta, por meio da qual a realidade pode ser representada na ausência dela própria, podendo tornar-se consciência dos impasses e relações do real. O signo também é parcialmente sensorial - pois depende, geralmente, de uma representação que o remete a algo fora de si mesmo -, mas é, antes de tudo, um sinal arbitrário, socializado e não coincidente com a sensação do objeto que representa.

Vigotski, na tentativa de criar uma ciência geral que integrasse os dados de muitas disciplinas particulares, e se inspirando nos estudos da atividade nervosa superior, edifica um modelo de funcionamento neuropsicológico que não se baseia na psicologia animal, mas a integra e condensa de forma original a enorme plêiade de fontes científicas, filosóficas e artísticas que ele conhecia. Era esse o seu projeto de psicologia, no qual, desde o princípio, a consciência não é uma qualidade de áreas específicas do cérebro humano. De fato, mesmo que o cérebro tenha novas áreas e haja um aumento de volume em outras, estas regiões não têm funções a priori. O signo transforma a formação do reflexo simples e, com o reflexo, compartilha apenas o fato de ser também uma conexão neural, embora de áreas não identificadas com a simples percepção do estímulo e a eliciação da resposta.

Uma das novas funções da palavra é o domínio do próprio comportamento que, geneticamente, supera o controle dos estímulos condicionados. No processo de aquisição de novas atividades, o controle do comportamento é internalizado a partir do domínio exercido por outras pessoas sobre a criança, por via da auto-estimulação proporcionada pelo signo - que, como vimos, é análogo, mas essencialmente diverso de um estímulo. Assim, na conduta superior:

1) o homem é parte da natureza, seu comportamento é um processo natural, a dominação do homem se estrutura como qualquer domínio da natureza, segundo o princípio de Bacon: a natureza se vence, obedecendo- $a$. Marx e Engels citam essas palavras ao falar das ferramentas de trabalho e dizem: "O homem utiliza as propriedades mecânicas, físicas e químicas das coisas que 


\section{Conceito de Consciência em Vigotski}

emprega como ferramenta para atuar sobre outras coisas de acordo com seu objetivo." (Marx \& Engels, citado por Vygotski, 1931/1995, p. 93).

2) Francis Bacon, Hegel, Marx e Engels serão referências filosóficas importantes para que a consciência seja vista, então, como parte da realidade natural - para que os princípios naturais de formação do reflexo condicionado, por exemplo, sejam incorporados e superados pelas formas culturais de organização da conduta; para que seja possível compreender a estrutura e a interação das neoformações neuronais humanas. A subordinação da natureza aos fins sociais estabelece uma tensão dialética para com a natureza interna existente em seu sistema de reflexo consciente.

Um vislumbre do monismo vigotskiano está na formação do ato volitivo: para ele, este é um problema conexo ao da consciência. No ato volitivo, devem-se diferenciar dois aparatos relativamente independentes: o primeiro corresponde ao próprio momento da decisão, quando se forma o aparato funcional e a subseqüente conexão reflexa. Neste momento, o sistema de ação consciente sopesa os motivos de decisão, utilizando os signos para representálos e analisá-los. A parte final do processo volitivo é a formação artificial do reflexo condicionado com a abertura de uma nova via nervosa. Já o segundo aparato seria o executivo, o funcionamento da conexão que se formou, a qual se processa de forma relativamente inconsciente (Vygotski, 1931/1995).

O autor produz modificações teórico-metodológicas importantes: na etapa final do seu método histórico-genético, iniciada por volta de 1928 (baseado em Beatón, 2005), propondo um conúbio de fontes de conhecimento que, unidas, constituem uma complexa teoria epistemo-ontológica do psiquismo humano e que, até hoje, circunscreve a abrangência temática desta teoria. Façamos um pequeno recorte: a pesquisa experimental de Vigotski procurava fundir a observação dos aspectos externos e internos da reação da criança e o processo pelo qual os sujeitos integravam os signos e/ou instrumentos introduzidos pelo experimentador para a resolução das atividades propostas. Subjetivo e objetivo são duas faces da mesma moeda: a experiência subjetiva esclarece como o cérebro organiza objetivamente a psique. A análise das lesões cerebrais locais no adulto, por exemplo, e o modo como impactavam a percepção, a memória, a própria condição do sujeito no seu meio social eram procedimentos usuais na clínica vigotskiana. Não se pode falar em consciência 
animal no referencial vigotskiano, devido ao papel das atividades especificamente humanas em seu desenvolvimento (Davidov \& Radzikhovskii, 1985) ${ }^{7}$. E o desenvolvimento é:

um complexo dialético que se distingue por uma complicada periodicidade, a desproporção no desenvolvimento das diversas funções, as metamorfoses ou transformação qualitativa de umas formas em outras, um entrelaçamento complexo de processos evolutivos e involutivos, o complexo cruzamento de fatores externos e internos, um complexo processo de superação de dificuldades e de adaptação. (Vygotski, 1931/1995, p. 141, tradução nossa)

Foi principalmente debatendo com autores de inspiração gestaltista, e também Kurt Lewin, com os quais Vigotski compartilhava uma concepção estrutural de desenvolvimento (Valsiner \& Van der Veer, 1996), que o autor completou sua concepção sobre as linhas gerais do desenvolvimento biológico e seu entrelaçamento com o cultural. Porém, na sua visão, o gestaltismo era biologicista, fisicalista e acrítico, e ele distanciou-se cada vez mais desta concepção.

Em todo caso, para Vigotski, a interação com o ser mais desenvolvido produz mudanças estruturais da consciência, predominantemente determinada por leis biológicas nas três primeiras etapas do desenvolvimento da criança, propostas por Bühler (etapas que já se mostram nos macacos antropóides pesquisados por Köhler) e reconhecidas por Vygotski (1995):

- instintos ou o fundo inato, hereditário, de seqüências de condutas programadas;

- adestramento ou etapa dos hábitos ou reflexos condicionados: reações aprendidas, adquiridas na experiência pessoal;

- intelecto ou reações intelectuais, que realizam a função de adaptação às novas condições. Karl Bühler tinha filiação gestaltista e desenvolveu a idéia desta etapa pela similaridade entre suas próprias observações de crianças e os experimentos de Köhler com primatas. Este último sustentava que os primatas apresentavam reações inteligentes, ausentes em outras espécies, como a utilização de objetos para alcançar outros objetos.

7 Foge aos objetivos deste artigo comentar os processos básicos de formação da conduta superior, mas se aplicam conceitos como zona de desenvolvimento real e próximo, situação social de desenvolvimento etc. 
Vygotski (1931/1995) acrescenta uma quarta etapa, a do desenvolvimento do domínio do próprio comportamento em que, como vimos no caso dos atos volitivos, nega dialeticamente as etapas primitivas e as conservam num nível superior de funcionamento. O próprio autor mostra-se indeciso sobre o termo adotado, perguntando-se: seria possível dizer que o desenvolvimento da vontade é uma simples etapa, quando se diferencia tão profundamente dos momentos anteriores do desenvolvimento? Não temos uma resposta definitiva do autor.

Um aspecto de certo modo contemplado nas etapas de Bühler era a convicção vigotskiana de que o desenvolvimento biológico nos provê com formas imediatas de comportamento, como a percepção, os afetos, a memória (Vygotski, 1931/1995); todas as funções elementares, que se confundem no animal e se diferenciam no desenvolvimento infantil. As reações instrumentais dos chimpanzés indicariam um passo evolutivo importante, embora fossem, para Vigotski, mais o último degrau da evolução animal que o mais confuso início da história da consciência humana. A distinção entre inferior e superior, por motivações tanto políticas quanto científicas, será posteriormente bastante criticada pela psicologia soviética.

Devemos dizer que estas três primeiras etapas estariam ainda subordinadas às leis biológicas da adaptação, embora exista uma clara superação por incorporação. As propriedades inerentes à primeira etapa do comportamento, por exemplo, se superam, se eliminam e se convertem em uma etapa contrária, superior, formando verdadeiras misturas de tipos de comportamentos.

As novas funções psíquicas, especificamente humanas, sociais e culturais, funções psíquicas superiores, formam-se neste processo de superação. Enlaçam os vários campos de investigação de Vigotski (1931/1995), que considerava as funções culturais mais antigas - como fazer nós em cordas para recordar - formas rudimentares das funções superiores, ficando na própria origem histórica destas formas, de tal modo que Vigotski (2001a) afirma: "Ela (a palavra) é a expressão mais direta da natureza histórica da consciência humana." (p. 486).

É assim que toda função psicológica superior, segundo Pino (2000), 
é uma relação social internalizada - na qual se diferenciam, como afirma Vygotski (1931/1995), dois grupos de fenômenos: 1) domínio dos meios externos do desenvolvimento cultural e pensamento; 2) desenvolvimento das funções psíquicas superiores especiais: atenção voluntária, memória lógica, formação de conceitos. Suas idéias foram amplamente esclarecidas, enriquecidas ou (muitas vezes) superadas pela neuropsicologia de Luria e outros cientistas soviéticos ${ }^{8}$. São funções de ação observável no exterior do homem e controladas de seu interior.

Imerso neste amplo quadro teórico que procura representar as mais complexas qualidades criativas do psiquismo humano, Vigotski esculpe, finalmente, um novo conceito de consciência. Este conceito é uma prenda de suas variadas fontes epistemológicas e, para muitos, era seu principal problema de pesquisa (Leontiev, 1996; Luria, 1986). Afirmando sua postura monista, materialista e dialética, proporciona uma alternativa à dicotomia entre objetivo e subjetivo na atividade; a consciência é processo e produto, passível de análises semióticas concretas e também em termos de interações sistêmicas cerebrais. Não coincide com a idéia de consciência política e moral (embora, este último sentido apareça raramente na Psicologia Pedagógica) nem simplesmente com o conhecimento científico. Aparece na obra vigotskiana, normalmente, com referência ao indivíduo - pois uma de suas acepções trata de um sistema psíquico que só pode realizar-se concretamente no indivíduo humano - mas as fontes de sua formação são sócio-históricas.

A consciência é sempre consciência socialmente mediada de alguma coisa (Vygotski, 1928-1933/1996): é a própria relação da criança com o meio, e, de modo mais tardio, da pessoa consigo própria (Luria, 1988). A consciência não é sistema estático, mecanicista: relaciona-se ao desenvolvimento da conduta voluntária. Conforme Toassa (2004), em Vigotski, na vida concreta o indivíduo pode modificar as condições que determinam sua conduta, criando uma nova solução; o processo de criação de um sentido, de uma interpretação para o mundo e suas relações já seria uma forma de criação de novas combinações: não é a realidade que simplesmente "se reflete" na consciência, mas também o indivíduo que a reconstitui ativamente e nela interfere, produzindo

8 Textos indicados: "Fundamentos de Neuropsicologia" e "Higher Cortical Functions in Man". Luria, sempre norteado pelo mestre, organiza uma tradição neuropsicológica que influencia, posteriormente, Oliver Sacks (1990). 
uma nova versão da realidade externa e das próprias vivências representadas na palavra. Diferentemente de outras teorias da Psicologia, o sistema da consciência para o autor não equivale à percepção, e se desdobra em duas acepções principais. Vejamos:

$1^{a}$ acepção: como um processo e seu produto. Neste sentido, o termo utilizado costumeiramente pelo autor é o de tomada de consciência com respeito ao meio, ao próprio eu e às vivências subjetivas, realizada por um complexo mecanismo psicológico. O termo é empregado na filosofia desde o século XVIII (Inwood, 1997, p. 78), sempre descrevendo uma relação. Trata-se de uma relação de compreensão ou conhecimento, ativa com respeito ao meio social e não de percepção, e tampouco de pensamento, como se costuma entender em outras psicologias. Demanda, contudo, uma consonância entre os fatos internos ou externos ao sujeito e sua representação, ainda que inconclusa ou imperfeita, na palavra - daí a idéia de compreensão. A percepção - mediada, e não imediata, como a animal - é apenas uma das funções psíquicas intermediárias deste processo de compreensão efetuado pelo sistema psicológico da consciência, que tem a palavra como sua célula (Vigotski, 1934/2001a); é, muitas vezes, o resultado de um longo processo de elaboração psicológica. A princípio, conforme Bruner (1985), em Vygotsky e outros autores a criança relaciona-se com a realidade através de uma consciência emprestada de terceiros acerca dos objetivos da atividade, dividida com a criança, e que constitui meio para seu próprio desenvolvimento.

Vygotski (1996) propõe momentos distintos para o desenvolvimento da consciência em crianças, que parte de um estado indiferenciado de atrações, afetos, sensações. Após o nascimento, o psiquismo vai conhecendo os estímulos que influem sobre ele, diferenciando coisas e pessoas, separando o subjetivo e o objetivo: no bebê pequeno, existiriam ainda manifestações muito primitivas de estados conscientes - a idéia de tomada de consciência é empregada nos mais variados contextos da obra de Vigotski, dos níveis mais simples aos mais complexos da ontogênese. Um dos exemplos deste uso: o autor assinala que o bebê precisa tomar consciência de que alguém cuida dele ${ }^{9}$ para poder engajar-se no processo de comunicação emocional (atividade fundamental do

9 Sendo a comunicação emocional a atividade principal no primeiro ano de vida e também a primeira formação sistêmica da consciência humana. 
primeiro ano de vida). Como próxima aquisição, num período subseqüente, a criança precisa separar figura e fundo na sua atividade psicológica.

O sistema psicológico consciente que caracteriza a primeira infância baseia-se na unidade entre afeto e percepção: a percepção une-se ao afeto e à ação. Em Vygotski (1928-1933/1996):

Para a criança na primeira infância a tomada de consciência não equivale a perceber e elaborar o percebido com a ajuda da atenção, da memória e do pensamento. Tais funções não estão diferenciadas, atuam na consciência integralmente subordinadas à percepção em tanto quanto participam no processo de percepção. (p. 344, tradução nossa)

Existem também outras classes de tomada de consciência, não identificadas necessariamente com um ou outro momento de desenvolvimento:

1) tomada de consciência motivacional: o termo é conexo ao da liberdade em Vigotski e aparece especialmente nas reflexões experimentais acerca da livre-eleição entre diversos motivos, ou situações de decisão em geral, seja em situações simples da vida prática (já se desenvolvendo em crianças pré-escolares), seja diante de sérios conflitos éticos, que desenvolvem a liberdade de escolha (baseado em Vygotski, 1995; 1996). Vigotski tece relações filosóficas, antropológicas e literárias nesta seara, e podemos deduzir que também os conflitos emocionais podem ser objetos de tomada de consciência, tendo como causas profundas o pensamento e a palavra socialmente mediados. A necessidade objetiva de resolver problemas e os próprios problemas surgem como circunstâncias históricas observadas e internalizadas por um indivíduo determinado.

2) tomada de consciência de operações semióticas e conceituais: a partir de estudos experimentais sobre o desenvolvimento do pensamento verbalizado, Vigotski (1934/2001a) afirma que tomar consciência de uma operação significa transportá-la do plano da operação ao plano da linguagem, recriá-la na imaginação para que seja possível exprimi-la em palavras. Na tomada de consciência, o processo de atividade é destacado da atividade geral da consciência, tornando-se, ele mesmo, um objeto de consciência, ou seja, apreendem-se os próprios processos psíquicos por meio da generalização e sistematização dos conhecimentos já existentes. Dilemas motivacionais poderiam, também, ser objeto de uma tomada de consciência sobre temas éticos bastante abstratos. 
Com a mediação do conceito, um objeto deixa de ser um estímulo em particular para ser conscientemente representado por uma síntese - para Vigotski, há então níveis mais abstratos de tomada de consciência (de percepção dos próprios sistemas semióticos), que são um tipo de meta-relação com a realidade, mediados especialmente por uma história de apropriação significativa dos conceitos científicos; nesta meta-relação podemos identificar uma relação com as conquistas do gênero humano e com as experiências individuais da pessoa. Neste processo, "a tomada de consciência passa pelos portões dos conceitos científicos" (1934/2001a, p. 290). Tais conceitos são mediados por outros conceitos, de modo que o objeto é colocado num sistema hierárquico de inter-relações semióticas; daí a possibilidade de que seja apreendido e transferido para outros campos do pensamento e de conceitos anteriormente não relacionados a ele. Esta idéia de transferência da informação entre sistemas lembra a primeira conceituação de consciência na obra de Vigotski.

Segundo o autor (1934/2001a), a generalização significa, ao mesmo tempo, tomada de consciência e sistematização de conceitos. É próprio dos conceitos espontâneos não serem conscientizados - as crianças sabem operar com eles, mas não tomam consciência deles, relacionando-se simplesmente com o objeto e não com o ato de pensamento que torna essa relação existente. Como podemos verificar, consciência não equivale à sensação:

Toda penetração mais profunda na realidade exige uma atitude mais livre da consciência para com os elementos dessa realidade, um afastamento do aspecto externo aparente da realidade dada imediatamente na percepção primária, a possibilidade de processos cada vez mais complexos, com a ajuda dos quais a cognição da realidade se complica e se enriquece. (Vigotski, 2000, p. 129)

Perceber de modo diferente significa também ganhar novas possibilidades de agir. O sentido da palavra, nova unidade de análise da consciência, é uma síntese de toda a ação deste sistema psicológico: o comportamento infantil passa a ser determinado pelo campo semântico interno; pelo uso da palavra, que, para Luria, em Vigotski significava a mudança da referência da palavra com relação ao objeto (1986). Exemplo: uma criança de 3 anos pode confundir supermercado e padaria, mas isso já não acontece com crianças maiores.

Note-se que os tópicos acima especificados não remetem a uma classificação acabada. Existem rupturas entre esses diversos níveis e formas de 
tomada de consciência, com um processo que se reflete dialeticamente no próprio desenvolvimento do sistema psicológico consciente, que comentarei no próximo tópico.

O termo autoconsciência também constitui parte do acervo semântico maduro de Vigotski (tendo se apresentado precocemente, como vimos num de seus primeiros textos), equivalendo a uma tomada de consciência relativa ao próprio eu, à própria personalidade. Uma das características da esquizofrenia seria a desagregação deste tipo de consciência, bem como da consciência da realidade objetiva (Vygotski, 1928-1933/1996). A autoconsciência desenvolve-se especialmente na adolescência, embora tenha suas aparições em torno dos 3 anos de vida, partindo da linguagem que os outros enunciam acerca da criança. Aqui, é possível identificar a influência hegeliana, e, possivelmente, engelsiana: o eu é um exemplo imediato de ser para-si. O homem se diferencia do animal e da natureza em geral por conhecer-se a si como "eu", e esta autoconsciência tem uma estrutura e dinâmica diferentes entre, por exemplo, adolescentes de classe sociais distintas.

Sobre a base da reflexão, da auto-consciência e compreensão dos processos próprios surgem novos agrupamentos, novas relações entre as ditas funções e precisamente estas relações que surgem na base da auto-consciência e que caracterizam a estrutura da personalidade nós as denominamos indícios terciários.... Todas as convicções internas, sejam quais forem, as diversas normas éticas, uns ou outros princípios de conduta plasmam-se, afinal de contas, na personalidade graças a esse tipo de relações. (Vygotski, 1928-1933/1996, p. 246, tradução nossa)

Um aspecto relevante neste trecho é que a tomada de consciência acontece pela operação de um mecanismo psicológico de caráter sintético, terciário, que se expressaria, também, numa organização cerebral determinada, terceira acepção do termo consciência em Vigotski.

$2^{a}$ acepção: como atributo. Vygotski qualifica diversas funções ou conteúdos psíquicos com o termo consciente: é comum encontrarmos idéias como concepção consciente (Vygotski, 1995), memória consciente, ato consciente; bem como o estado existente ou inexistente de uma relação de compreensão com a realidade externa ou vivencial. Também utiliza a idéia de estado psíquico consciente referindo-se ao estado de vigília de uma pessoa.

$3^{a}$ acepção: como sistema psicológico em relação com o meio e com 
a própria pessoa. Um tipo de mecanismo que se desenvolve e resulta em graus variáveis de tomada de consciência que integra sistemas novos e antigos de conduta. Nas palavras de Vigotski (1934/2001a): "Para a psicologia moderna, não é nenhuma novidade que a consciência é um todo único e que funções particulares estão inter-relacionadas em sua atividade." (p. 2), e "a consciência se desenvolve como um processo integral, modificando a cada nova etapa a sua estrutura e o vínculo entre as partes." (p. 283), deste desenvolvimento resultando graus variáveis de tomada de consciência. Luria (1988) utiliza o termo sistema estrutural com função semântica para explicar o conceito vigotskiano. O mesmo autor (2001a, p.204) destaca a necessidade da análise objetiva da atividade consciente do paciente no mundo. Na sua face biológica, sintetiza a ação das funções da matéria altamente organizada no cérebro, expressão subjetiva da atividade cerebral (Vygotski, 1924-1934/1991).

Para Valsiner e Van der Veer (1996), é a Goldstein que Vigotski toma de empréstimo a idéia de sistema funcional como negação do antigo localizacionismo cerebral, que legava a cada área encefálica um papel desligado do todo de sua atividade. Vigotski, aluno de medicina por um curto período e instrumentalizado pelos debates neuropsicológicos que desenvolvia com sua equipe, entende que as principais mudanças que distinguem as funções psíquicas superiores das biológicas, imediatas, são as ligações interfuncionais, mais do que a modificação de funções isoladas: a memória associativa funcionaria isoladamente; a lógica, formando conexões complexas com o raciocínio e a percepção. Tal como no princípio de sua obra, a palavra sofre o impacto de todas estas funções. A formação destas novas conexões funcionais é mérito das atividades mediadoras. Para Vygotski (1931/1995), os fenômenos morfológicos e fisiológicos, a forma e a função, condicionam-se reciprocamente (p. 124). Podemos deduzir que tais estruturas, num nível de atividade mais simples, seriam as principais responsáveis pelas reservas naturais do psiquismo: o desencadeamento do instinto, a formação de reflexos condicionados, as reações intelectuais. A primazia hierárquica ficaria por conta das zonas responsáveis pela volição e pela organização da conduta baseadas na fala, especialmente, dos lobos frontais, mas as relações entre centros corticais e subcorticais do cérebro seriam de mútua influência.

Na terceira acepção do termo, a consciência é, pois, um único siste- 
ma psicológico, composto pelas estruturas de conduta consciente (sinônimo de funções psíquicas superiores); verdadeiras relações sociais internalizadas como ações, representações e palavras que, encaradas em si mesmas, podem ser tidas como sistemas específicos - a consciência é, portanto, uma estrutura composta de outras estruturas. Desenvolve-se com modificações da estrutura geral e de vínculo entre seus elementos, os quais mantêm entre si uma relação dialética de parte-todo, criada pela inserção dos sujeitos nas atividades sociais. Integrando-se a novas atividades humanas, as pessoas apropriam-se das funções psíquicas superiores que as medeiam: memória, atenção, linguagem oral, sentimento, linguagem escrita etc.

Inúmeras impressões sensoriais bombardeiam o cérebro. Tais impressões são trabalhadas pelas funções psíquicas superiores, cuja atividade consciente consiste em atribuir sentido às impressões sensoriais, em produzir novas combinações dessas impressões, além de controlar as ações. O caráter voluntário e criativo da atividade cerebral permite, assim, dizer que a realidade reflete-se não apenas no, mas também pelo cérebro. Este processo desenvolvese graças à mediação da experiência acumulada e sintetizada na linguagem: é com a apropriação dos sistemas de significações historicamente desenvolvidos que as pessoas são capazes de ir além das sensações, generalizando a experiência nas palavras. Os signos são estímulos artificialmente criados para a representação dos estímulos-objeto (coisas, pessoas) e para a acumulação de experiências acerca do meio: o caminho da criança à coisa, e da coisa à criança passa por outra pessoa.

Um problema conexo ao da consciência seria o da inconsciência ou inconsciente. Vigotski (1925/2001b) não negava a existência do inconsciente e sua influência na conduta, mas criticava Freud e a Psicanálise pela tendência a sexualizar toda a forma de inconsciente e a hiperbolizar este conceito, que merece maior atenção do que podemos lhe dedicar neste momento.

Concluindo: este artigo procurou identificar o trajeto histórico do conceito de consciência em Vigotski. A importância da socialidade, as origens da autoconsciência nas relações sociais e o caráter sistêmico deste sistema psicológico são algumas características de suas primeiras idéias sobre consciência que se preservam na sua conceituação mais madura do termo. Em vivo debate com uma psicologia em crise, lançou os fundamentos de uma psicologia marxista e 


\section{Conceito de Consciência em Vigotski}

libertária, preservando contribuições importantes da psicologia russa e de muitas outras iluminações. Com este artigo, aqui finalizo minha pesquisa de quatro anos acerca do conceito de consciência em Vigotski, iniciada ainda no mestrado.

Cabe ainda uma nota sobre o destino histórico das obras do autor: após a morte de Lênin, em 1924, iniciou-se a disputa pelo poder na cúpula do partido unido soviético, que terminaria com a expulsão de Trotski e ascensão de Stalin (Reis Filho, 2003). Acentuou-se a perseguição ideológica em muitos campos de conhecimento: vários discípulos de Vigotski, segundo Kozulin (1994), criticam-no antes e depois de sua morte, criando uma psicologia baseada no conceito de atividade prática - mas a posição de Kozulin (1994), entretanto, é alvo de grande polêmica, cuja exposição foge aos limites deste artigo. O stalinismo atacará a pedologia ${ }^{10}$ e qualquer iniciativa de educação científica que se oponha ao modelo escolástico, patriótico e ideológico do momento; ora, Vigotski era um entusiasta de qualquer avanço na psicologia, viesse ou não da União Soviética (Alvarez \& Río, 1991, p. xiv). A ideologia oficial, de modo similar ao behaviorismo americano, via com reticências a valorização do tema "consciência" pelo autor. Outro agravante teria sido a ambição de Stálin em ser um cientista da linguagem. Resultado: Vigotski foi silenciado por cerca de 20 anos após sua morte, e, a partir de 1950, o pavlovismo torna-se uma psicologia oficial.

Mas Stálin morre em 1953 e, em resposta ao florescimento do cognitivismo norte-americano, fortalece-se a temática da linguagem como "segundo sistema de sinais" na conceituação pavloviana. A era stalinista é colocada em xeque. A partir de então, são editados alguns livros de Vigotski, como Pensamento e Linguagem (1956) e Psicologia da Arte (1968), conforme Alvarez e Río (1991).

Outra censura sobre a obra vigotskiana, mais insidiosa que aquela à qual foi submetida na União Soviética, é a ocidental. Esta se iniciou em 1962, data conhecida da primeira publicação de um livro seu no Oeste do mundo, capitaneada por Bruner (1962): censura que consiste na mutilação editorial, esvaziamento político ou simplesmente confusão com outras abordagens, como o cognitivismo, construtivismo ou construcionismo. Mas Vigotski é um autor marxista, conquanto muito distante de extrações deterministas do marxismo, como aquelas de Stálin ou Kautsky. Suas falas são pesadas na crítica à forma de

10 Ciência geral da criança, à qual se alinhava Vigotski. 
vida burguesa e entusiástica no planejamento de uma sociedade socialista, em que a consciência do homem sobre seu mundo, si mesmo e suas próprias ações deveriam ser objeto de estudo e contribuição importantes da Psicologia.

Toassa, G. (2006). The concept of consciousness in the Vygotski's theory. Psicologia USP, 17(2), 59-83.

Abstract: This article investigates the concept of consciousness in the work of Lev Vygotsky, which is the main problem of his psychology. It summarizes the importance of the political and social context of the Soviet Union for the development of his theory, which has begun with influences from the reflexology and pavlovism. However his conception was constructed with a progressive integration of his wide range of knowledge, embracing arts, marxist, classical philosophy, neuropsychology and experimental psychology. Through readings of vygotskyan's works produced from 1924 up to 1934, this article revises the semantics occurrences of the word "consciousness", identifying its monist and materialist dialectic fundaments, extracting its main senses and including it in historical-cultural perspective. The concept is divided in three fundamental senses (process of becoming aware of the internal and external reality; attribute of psychological contents and processes; psychological system) which link it selves, laying the foundations of the general psychology of Vygotsky and relating neuropsychology, ethics and ontology.

Index terms: Vygotsky, Lev Semenovich, 1896-1934. Conscience. History of psychology. Neuropsychology. Luria, Alexander Romanovich, 1902-1977.

Toassa, G. (2006). Le concept de conscience chez Vigotski. Psicologia USP, 17(2), 59-83.

Résumé: Cet article poursuit le concept de conscience au long de l'oeuvre 


\section{Conceito de Consciência em Vigotski}

de Vigotski, où il joue le rôle principal. L'article fait aussi un résumé de l'importance du contexte socio-politique de l'Union Soviétique dans le développement de sa théorie, qui a commencé sous l'influence de la réflexologie et du pavlovisme, et a réussi progressivement à intégrer les vastes connaissances de l'auteur (dans le champ des arts, de la philosophie classique et marxiste) jusqu'à la neuropsychologie expérimentale. Par la lecture des travaux produits entre 1924 et 1934, l'article passe en revue les occurences sémantiques du mot conscience, essayant d'identifier ses fondements monistes et matérialistes, d'extraire ses sens principaux et d'inclure le concept dans la visée historico-sociale. Le concept se present a partir de trois acceptions de base (à savoir, le processus de prise de conscience de la réalité externe et interne; l'attribut de contenus et de processus psychologiques; le système psychologique) qui s'articulent, en produisant un des fondements de la psychologie générale vigotskienne et en articulant de la neuropsychologie, de l'éthique et de l'ontologie.

Mots-clés: Vygotsky, Lev Semenovich, 1896-1934. Conscience. Histoire de la psychologie. Neuropsychologie. Luria, Alexander Romanovich, 1902-1977.

\section{Referências}

Almeida, S. H. V. (2004). O conceito de memória na obra de Vigotski. Dissertação de Mestrado, Pontifícia Universidade Católica de São Paulo, São Paulo.

Alvarez. A., \& Río, P. (1991). Prólogo a la edición en lengua castellana. In Obras escogidas (Vol. 1, pp. 13-26). Madrid: Visor.

Beatón, G. A. (2005). La persona en el enfoque historico cultural. São Paulo: Linear B.

Bruner, J. (1985). Vygotsky: A historical and conceptual perspective. In J. Wertsch (Ed.), Culture, communication and cognition: Vygotskian perspectives (pp. 21-34). Cambridge: Cambridge University Press.

Davidov, V. V. \& Radzikhovskii, A. (1985). Vygotsky's theory and the activity-oriented approach in psychology. In J. Wertsch (Ed.). Culture, communication and cognition: Vygotskian perspectives (pp. 35-65). Cambridge: Cambridge University Press.

Duarte, N. (2001). Educação escolar, teoria do cotidiano e a escola de Vigotski (3a ed.). Campinas, SP: Autores Associados.

Engels, F. (1880). Socialism: Utopian and Scientific. Recuperado em 27 de março de 2006, de http://www.marxists.org/archive/marx/works/1880/soc-utop/int-mat.htm 


\section{Gisele Toassa}

Inwood, M. (1997). Dicionário Hegel. Rio de Janeiro: Jorge Zahar.

Kozulin, A. (1994). La psicologia de Vygotski. Madrid: Alianza Editorial.

Leontiev, A. N. (1996). Artigo de introdução sobre o trabalho criativo de L. S. Vigotski. In L. S. Vigotski, Teoria e método em psicologia (pp. 425-470). São Paulo: Martins Fontes.

Luria, A. R. (1986). Pensamento e linguagem: as últimas conferências de Luria. Porto Alegre: Artes Médicas.

Luria, A. R. (1988). O cérebro humano e a atividade consciente. In L. S. Vigotski, A. R. Luria, \& A. N. Leontiev, Linguagem, desenvolvimento e aprendizagem (pp. 191-228). São Paulo: Ícone.

Luria, A. R. (1992). A construção da mente. São Paulo: Ícone. (Trabalho original publicado em 1979)

Nobel Foundation. (1967). Nobel lectures, physiology or medicine 1901-1921 (Vol. 1). Recuperado em 02 de janeiro de 2006 de http://nobelprize.org/medicine/laureates/1904/ pavlov-bio.html

Pavlov, I. P. (2005). O reflexo condicionado. In I. P. Pavlov, Textos escolhidos (pp. 75-100). São Paulo: Abril Cultural. (Trabalho original publicado em 1934)

Pessotti, I. (1979). Introdução. In I. P. Pavlov, Psicologia. São Paulo: Ática.

Pino, A. (2000, julho). O social e o cultural na obra de Vigotski. Revista de Educação e Sociedade, 21(71), 45-78.

Reis Filho, D. A. (2003). As revoluções russas e o socialismo soviético. São Paulo: UNESP.

Sacks, O. (1990). Luria and "Romantic Science". In E. Goldberg (Ed.), Contemporary neuropsychology and the legacy of Luria (pp. 181-194). London: Laurence Erlbaum.

Shuare, M. (1990). La psicología soviética tal como yo la veo. Moscou: Editorial Progresso.

Toassa, G. (2004). Conceito de liberdade em Vigotski. Psicologia: Ciência e Profissão, 24(3), 2-11.

Valsiner, J., \& Van Der Veer, R. (1996). Vygotsky: uma síntese. São Paulo: Loyola.

Vigotski, L. S. (1999). O desenvolvimento psicológico na infância. São Paulo: Martins Fontes.

Vigotski, L. S. (2000, julho). Psicologia concreta do homem. Revista Educação \& Sociedade, 21(71). (Texto original de 1929)

Vigotski, L. S. (2001a). A construção do pensamento e da linguagem. São Paulo: Martins Fontes. (Trabalho original publicado em 1934) 


\section{Conceito de Consciência em Vigotski}

Vigotski, L. S. (2001b). Psicologia da arte. São Paulo: Martins Fontes. (Trabalho original publicado em 1925)

Vigotski, L. S. (2001c). Psicologia pedagógica. São Paulo: Martins Fontes. (Trabalho original publicado em 1926)

Vigotski, L. S., \& Luria, A. R. (1996). Estudos sobre a história do comportamento: o macaco, o primitivo e a criança. Porto Alegre: Artes Médicas. (Trabalho original publicado em 1930)

Vygotski, L. S. (1995). Historia del desarollo de las funciones psíquicas superiores. In Obras escogidas. Madrid: Visor Distribuiciones. (Trabalho original publicado em 1931)

Vygotski, L. S. (1987). La imaginación y el arte en la infancia. México, DF, Hispânica. (Trabalho original publicado em 1931)

Vygotski, L. S. (1991). Obras escogidas (Vol. 1). Madrid: Visor. (Trabalho original proferido entre 1924-1934)

Vygotski, L. S. (1996). Obras escogidas (Vol. 4). Madrid: Visor. (Trabalho original proferido entre 1928-1933)

Vygotsky, L. S. (1994). A formação social da mente (5a ed.). São Paulo: Martins Fontes.

Recebido em: 3.05 .2006

Aceito em: 19.06.2006 